\title{
Toward a Core Outcome Set for Head, Neck, and Respiratory Disease in Mucopolysaccharidosis Type II: Systematic Literature Review and Assessment of Heterogeneity in Outcome Reporting

\author{
Aleksandra Metryka, BSc, MSc, PhD', Nailah Brown, BSc (Hons), MPhil', \\ Jean Mercer, EN, RGN, RSCN ${ }^{2}$, Stuart Wilkinson, MBChB, MRCPCH ${ }^{3}$, \\ Simon Jones, BSc, MBChB, MRCPCH ${ }^{2}$, Paula Williamson, BSc, $\mathbf{P h D}^{4}$, and \\ lain Bruce, BSc, MBChB, MRCS, MD ${ }^{1,5}$
}

\begin{abstract}
The mucopolysaccharidoses (MPS) are a relatively uncommon group of inherited metabolic disorders, with significant negative implications for life span and aspects of quality of life. Their rarity means that producing evidence to guide best practice has often entailed assimilating findings from multiple studies. Core outcome sets (COS) are being increasingly used across medicine as a potential solution to the problems arising from heterogeneous reporting of outcomes in effectiveness studies. A COS is a recommended minimum set of outcomes that should be measured for a given condition in an effectiveness study, with the ultimate aim of increasing the value of clinical information by enabling meaningful comparison and combination of data from various sources. A systematic review identified $4 \mathrm{I}$ outcomes measured in published studies and ongoing and completed clinical trials, with individual outcomes being measured using a variety of measurement instruments/tools. This work represents the important initial steps in the development of COS for head, neck, and respiratory disorders in MPS type II, raising awareness of the extent of heterogeneity in outcome reporting and determining the scope of outcomes and corresponding instruments currently used. The next step will be to use the generated "longlist" of outcomes to develop an electronic Delphi prioritization exercise with the intention of reaching a consensus regarding the most important outcomes to measure in effectiveness studies for head, neck, and respiratory disease in MPS type II.
\end{abstract}

\section{Keywords}

core outcome set, systematic review, mucopolysaccharidosis, outcome domain, outcome measure instrument

\footnotetext{
' Paediatric ENT Department, Royal Manchester Children's Hospital, Manchester University Hospitals NHS Foundation Trust, Manchester Academic Health Science Centre, Manchester, UK

${ }^{2}$ Willink Biochemical Genetics Unit, Manchester Centre for Genomic Medicine, St. Mary's Hospital, Manchester University Hospitals NHS Foundation Trust, Manchester Academic Health Science Centre, Manchester, UK

${ }^{3}$ Paediatric Respiratory Department, Royal Manchester Children's Hospital, Manchester University Hospitals NHS Foundation Trust, Manchester Academic Health Science Centre, Manchester, UK

${ }^{4}$ MRC North West Hub for Trials Methodology Research, Institute of Translational Medicine, University of Liverpool, Liverpool, UK

${ }^{5}$ Division of Infection, Immunity and Respiratory Medicine, Faculty of Biology, Medicine and Health, University of Manchester, Manchester, UK
}

Received August 07, 2018. Accepted for publication September 04, 2018.

Corresponding Author:

Aleksandra Metryka, PhD, Paediatric ENT Department, Royal Manchester Children's Hospital, Manchester University Hospitals NHS Foundation Trust, Manchester Academic Health Science Centre, Oxford Road Manchester, MI3 9WL, UK.

Email: aleksandra.metryka@mft.nhs.uk 


\section{Background}

The mucopolysaccharidoses (MPS) are a family of inherited metabolic disorders, caused by specific lysosomal enzyme deficiencies, with resultant accumulation of partially degraded glycosaminoglycans (GAG) within tissues. ${ }^{1}$ The ubiquitous nature of GAG within the body means that a number of different organ systems can be affected. Eleven distinct types of MPS disorders have been classified, according to the particular enzyme that is deficient. ${ }^{1-3}$

Involvement of the upper and lower respiratory tract in MPS type II results in significant airway compromise, with progressive airway obstruction being responsible for a significant proportion of the morbidity and mortality associated with this condition. ${ }^{4}$ Airway disease is characterized by adenotonsillar hypertrophy, macroglossia, recurrent upper respiratory tract infections, thickened nasal mucosa, airway deposits, and tracheomalacia. $^{5-7}$ These changes within the airway are considered to result from GAG accumulation in soft tissues. ${ }^{5}$ Sleep disordered breathing, or obstructive sleep apnoea, has been reported in $90 \%$ (27/30 patients) of patients with MPS type II when tested using polysomnography. ${ }^{8}$ Obstructive events during sleep can lead to learning impairment, behavioral problems, developmental, and learning delay as well as cardiovascular disease (pulmonary hypertension and right ventricular hypertrophy). ${ }^{9}$ Skeletal abnormalities (eg, small ribs and short neck), enlarged internal organs, restrictive lung disease, neurocognitive impairment, and cardiac disease may further compound multilevel upper airway involvement, leading to respiratory compromise that may significantly restrict lifestyle and ultimately lead to death. ${ }^{5,6}$

Hearing loss is a universal finding in MPS, with a third of patients having severe profound hearing loss. ${ }^{10}$ More is understood about the hearing loss in MPS type II in comparison with the other subtypes, due to the publication of hearing data from an international observational study (The Hunter outcome survey $[\mathrm{HOS}]) .{ }^{11}$ At the time of reporting, $84 \%$ (70/83) of the children surveyed had a hearing loss; $24 \%$ (20/83) had a mild hearing loss, $31 \%(26 / 83)$ a moderate loss, $22 \%(18 / 83)$ a severe loss, and $7 \%(6 / 83)$ a profound loss (WHO-ICIDH criteria). The conductive component of the hearing loss in MPS type II is predominantly related to an increased tendency toward the development and persistence of otitis media with effusion (OME, glue ear) and recurrent acute otitis media (rAOM). In MPS type II, GAG deposits are believed to accumulate within the nasopharynx contributing to Eustachian tube dysfunction (ETD) and the development and persistence of OME. The increased tendency toward upper respiratory tract infections in MPS may manifest as chronic adenoiditis, further contributing to ETD and AOM. The tendency toward OME may last into adolescence and adulthood in MPS. Long- and short-term ventilation tubes and hearing aids have been used in the management of persistent OME with hearing loss, ${ }^{10,12,13}$ with greater emphasis now being placed on hearing aids due to the anticipated longevity of OME and the attendant risk of recurrent general anaesthesia.
There is an unmet need for strong clinical evidence to guide treatment of head, neck, and respiratory disease in MPS disorders, with much of the published evidence reflecting the experience of larger centres based on the retrospective analysis of patient outcomes.

A Core Outcome Set (COS) describes the minimum outcome data that should be measured in a clinical study for a particular condition. ${ }^{14}$ The lack of an agreed COS for MPS type II in general, and specifically respiratory/head and neck disease, crucially hinders comparison between studies. In addition, purchasers and regulatory bodies are likely to prefer evidence from clinical studies that adhere to an agreed set of outcome measures. There is also a paucity of information detailing patient and parent perspectives on the symptomatology of MPS disorders. The ideal COS for respiratory/head and neck disease associated with MPS type II would combine both patient/parent and clinician opinion and could be used in the design of all subsequent clinical studies. Currently, the tendency to only report those findings that researchers consider to be significant or positive can lead to outcome reporting bias (ORB). ${ }^{15}$ The development of a COS can help to negate the effect of ORB in future study designs and limit heterogeneity of chosen outcomes in studies investigating different interventions in the same organ system.

The aim of this systematic literature review was to generate a "long list" of outcome measures and corresponding list of outcome measurement instruments reported in the MPS type II literature for respiratory/head and neck disease. This information would help to determine the extent of heterogeneity of outcome reporting in this MPS subtype and enable the subsequent development of a COS specific for respiratory/head and neck disease.

\section{Methods}

\section{Literature Search}

Studies were identified using a systematic search strategy applied to EMBASE, MEDLINE, and CINAHL (using http://www.library.nhs.uk/hdas) over the 24-year period (1990-2014). The time period selected represents contemporary practice and current understanding of the disease, reflecting the introduction of disease-modifying therapies, along with centralized, coordinated, and multidisciplinary care.

Multiple databases were used to maximize the sensitivity of the search. Within EMBASE, MEDLINE, and CINAHL a Medical Subject Headings (MeSH) search (mapped to the Thesaurus) was performed. Within the Thesaurus, the subject heading was "exploded" and the "OR" setting applied. The general MeSH headings (Table 1) was subsequently combined with the mucopolysaccharidosis (MPS) II MeSH heading using the "AND" option.

The COS being developed is specifically for 2 interrelated body systems (respiratory and head and neck) within MPS type 
Table I. MeSH headings for systematic review search.

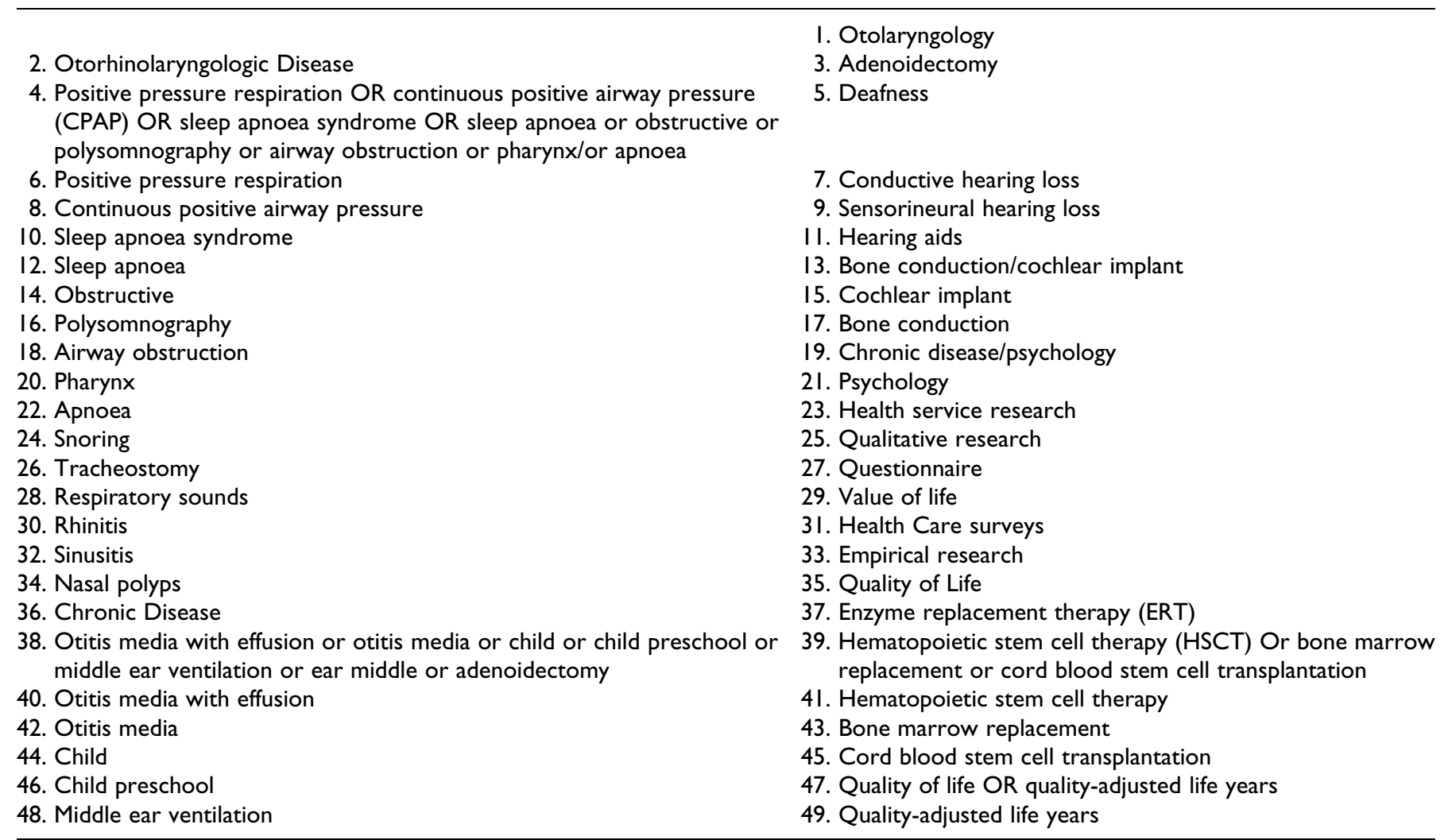

Abbreviation: MESH, Medical Subject Headings.

II. Reflecting our understanding of the literature, it was considered necessary to include a range of study types in order to achieve a meaningful summary of outcomes used in studies related to these 2 body systems. We were concerned that the information contained in abstracts for less formal study designs might be insufficient to appropriately screen, and formal studies may not include all outcomes in the abstract. As such, a search strategy using additional general MESH headings considered relevant to these body systems was chosen with the aim of limiting reliance upon the quality of abstracts at the screening stage.

The following limits were applied to the search strategy:

- 1990 to 2014

- English language only

- Human only

\section{Clinical Trials Registry Search}

The World Health Organization (WHO) International Clinical Trials Registry Portal (http://apps.who.int/trialsearch/, last accessed January 02 2018) and ClinicalTrials.Gov (https://clinicaltrials.gov/, last accessed January 02 2018) were searched for Mucopolysaccharidosis II. This search revealed 45 and 10 results from the ClinicalTrials.gov and WHO databases, respectively. Both open and closed trials were included.

\section{Inclusion Criteria}

Any otolaryngology surgical or medical intervention in patients with MPS II was included, along with studies focusing on ERT and HSCT. We also included all systematic reviews with/without meta-analyses, randomized controlled trials, casecontrolled trials, case series, prospective cohorts, and review articles.

\section{Exclusion Criteria}

We excluded studies that were not specifically related to MPS type II, studies that did not investigate or report respiratory/ head and neck disease in patients with MPS type II (the exception to this were papers looking at bone marrow transplant [BMT] and HSCT), case series with fewer than 3 patients, expert opinion papers, discussion papers, and consensus papers. 
Journal of Inborn Errors of Metabolism \& Screening

\section{Study Selection}

Two researchers (J.M. and N.B.) independently reviewed the abstracts produced by the above-mentioned literature search strategy, and a comprehensive list of studies was obtained. The full-text articles of studies that appeared to fit the inclusion criteria and those that have insufficient information in the title and abstract were obtained. The articles were assessed independently by the 2 reviewers (J.M. and N.B.). Any disagreement between the reviewers regarding including the inclusion of a paper was resolved through discussion. Where agreement was not reached, a third reviewer was consulted (I.A.B.).

The reference section of each paper was cross-referenced to identify any further relevant papers. Outcomes relevant to respiratory/head and neck disease were identified in published studies involving patients with MPS type II, receiving either medical or surgical interventions. Clinical trials were reviewed by one researcher (A.M.) and were included if they measured outcomes relevant to respiratory/head and neck disease in patients with MPS type II.

\section{Results}

The systematic review of relevant literature was performed. Databases EMBASE, MEDLINE, and CINAHL were searched from 1990 to 2014. Literature search yielded 228 results which subsequently were reduced to 90 records following the removal of 138 duplicates. Of 90 publications following the thorough screening process of abstracts against inclusion and exclusion criteria, further 68 results were excluded. Consequently, 22 publications were left. Full-text articles were collected for those 22 results, and they were assessed using the inclusion and exclusion criteria. The total of 10 full-text articles were excluded for the following reasons: 7 results had less than 3 patients, 1 result was a consensus paper, 1 result was a review article, and 1 publication was a duplicate study published in 2 different journals under a different name. Ultimately 12 publications were identified and reviewed for outcomes (Figure 1).

A total of 55 clinical trials were identified following a clinical trials registry search for "Mucopolysaccharidosis II." Five trials were duplicated between the databases. Of the remaining 50 clinical trials, 7 studies did not investigate MPS type II. Among the remaining 43 trials, 4 studies were already included in the literature search, and 33 studies did not consider any respiratory/head and neck disease outcomes. Following the review process, 6 clinical trials were identified and outcomes measured were included in this review (Figure 1). Of particular note, the clinical trial NCT03292887 reported data from the Hunter Outcome Survey (HOS). The HOS collects a wealth of data on patients with MPS type II who are or have been treated with ERT (Elaprase) or those who receive no treatment at all. Data collection began in 2005, and it is anticipated to continue for a minimum of 17 years. In addition to general outcomes (eg, GAG status and mobility), HOS collects information about respiratory and ENT outcomes.
One publication identified during the systematic literature search have reported on HOS findings relating to otological outcomes. ${ }^{11}$

A total of 41 outcomes were extracted (Table 2). The HOS collects 26 outcomes, and the remaining studies reported between 1 and 8 outcomes. The most frequently reported outcome was exercise tolerance, which was reported by 9 out of 17 studies, followed by pulmonary function, which was reported by 8 of the 16 reviewed studies, while sleep apnoea and hearing were assessed in 4 and 5 research studies, respectively (see Table 2 for references). Identified outcomes were subsequently organized according to the most recent $\mathrm{COS}$ taxonomy (Table 3). ${ }^{16}$ Such classification of outcomes will be presented to stakeholders in the next stage of this project of COS identification, the electronic Delphi (eDelphi) exercise.

\section{Discussion}

Mucopolysaccharidosis type II is rare with an incidence of approximately 1 per 100000 male births. In the period between 1992 and 2002, 52 babies with Hunter syndrome were born in the United Kingdom (http://www.mpssociety.org.uk/diseases/ mps-diseases/mps-ii/). The rarity of this condition makes it difficult to obtain sufficient amounts of good-quality data to guide practice and decision-making, both for clinicians and for carers alike. Currently, we are reliant on case series from larger tertiary referral centers to support evidence-based practice, with only limited conformity in choice of outcome reporting. Pathology found in MPS type II may affect both the lower and the upper aerodigestive tract, and we suggest that combining assessments of both has direct clinical application. Mucopolysaccharidosis type II is an expensive disease to treat; ERT has been reported by de Bitencourt to cost over $£ 100000$ per year for a child and twice as much for an adult. ${ }^{26}$ It is difficult to assess "value for money" when the evidence for efficacy is so limited.

The core outcome measures in effectiveness trials (COMET) initiative (http://www.comet-initiative.org) promotes standardization of outcome reporting in research, supporting researchers in developing COS. A COS is an agreed standardized collection of outcomes, which should, as a minimum, be measured and reported in all trials in a specific clinical area. Core outcome measures in effectiveness trials also provide a database resource for researchers and patients, detailing what COS have been, or are being developed for a particular medical condition or intervention. This study was the first step toward determining a COS for head, neck, and respiratory disease for patients with MPS type II. This systematic literature review highlights the extent of heterogeneity in outcome reporting, in terms of both outcome measures and corresponding outcome measurement instruments.

It is important to note that only 2 publications and 2 clinical trials considered QoL as an outcome. ${ }^{20,24}$ One of the publications was a systematic review that established QoL as one of its 
Table 2. Long-list of outcome measures and corresponding outcome measurement instruments (OMI).

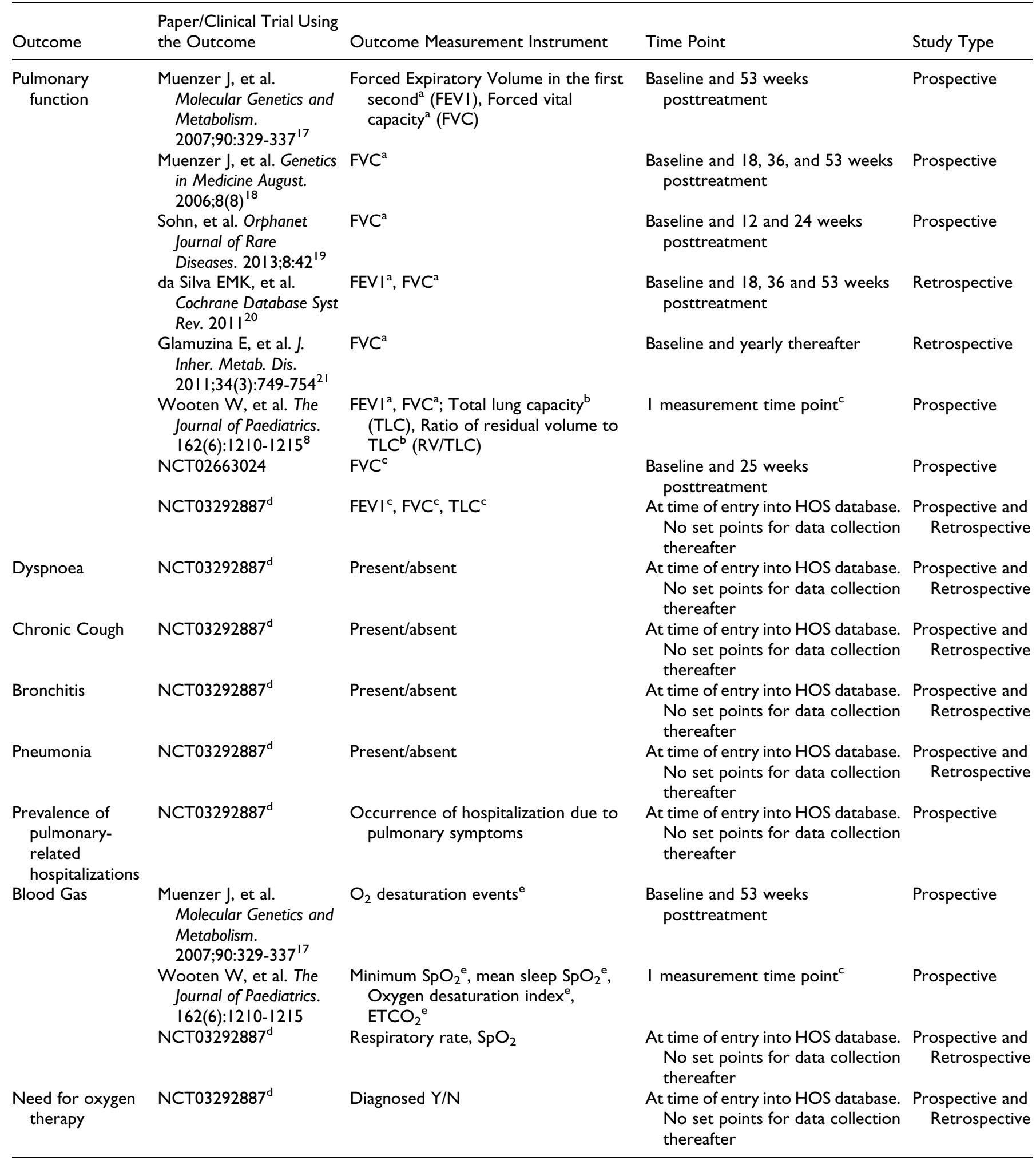


Table 2. (continued)

\begin{tabular}{|c|c|c|c|c|}
\hline Outcome & $\begin{array}{l}\text { Paper/Clinical Trial Using } \\
\text { the Outcome }\end{array}$ & Outcome Measurement Instrument & Time Point & Study Type \\
\hline \multirow[t]{4}{*}{ Sleep apnoea } & $\begin{array}{l}\text { Muenzer J, et al. } \\
\text { Molecular Genetics and } \\
\text { Metabolism. } \\
\text { 2007;90:329-337 }\end{array}$ & Apnoea-hypopnoea index $(\mathrm{AHI})^{\mathrm{ef}}$ & $\begin{array}{l}\text { Baseline and } 53 \text { weeks } \\
\text { posttreatment }\end{array}$ & Prospective \\
\hline & $\begin{array}{l}\text { da Silva EMK, et al. } \\
\text { Cochrane Database Syst } \\
\text { Rev. 20II }\end{array}$ & Overnight $\mathrm{AHI}^{\mathrm{e}}$ & Not reported & Retrospective \\
\hline & $\begin{array}{l}\text { Wooten W, et al. The } \\
\text { Journal Of Paediatrics. } \\
\text { 162(6): } 1210-1215\end{array}$ & $\mathrm{AHI}^{\mathrm{ef}}$ & I measurement time point ${ }^{c}$ & Prospective \\
\hline & NCT03292887 & Diagnosed $\mathrm{Y} / \mathrm{N}$ & $\begin{array}{l}\text { At time of entry into HOS database. } \\
\text { No set points for data collection } \\
\text { thereafter }\end{array}$ & $\begin{array}{l}\text { Prospective and } \\
\text { retrospective }\end{array}$ \\
\hline & $\begin{array}{l}\text { Muenzer J, et al. Genetics } \\
\text { in Medicine. 2006;8(8) }\end{array}$ & \multirow[t]{2}{*}{ 6MWT } & $\begin{array}{l}\text { Baseline and } 18,36 \text { and } 53 \text { weeks } \\
\text { posttreatment }\end{array}$ & Prospective \\
\hline & $\begin{array}{l}\text { Sohn, et al. Orphanet } \\
\text { Journal of Rare } \\
\text { Diseases. 2013;8:42 }\end{array}$ & & $\begin{array}{l}\text { Baseline and } 12 \text { and } 24 \text { weeks } \\
\text { posttreatment }\end{array}$ & Prospective \\
\hline & $\begin{array}{l}\text { da Silva EMK, et al. } \\
\text { Cochrane Database Syst } \\
\text { Rev. 20II }\end{array}$ & 6MWT & $\begin{array}{l}\text { Baseline and } 18,36 \text { and } 53 \text { weeks } \\
\text { posttreatment }\end{array}$ & Retrospective \\
\hline & $\begin{array}{l}\text { Glamuzina E, et al. J. } \\
\text { Inher. Metab. Dis. } \\
\text { 20I I;34(3):749-754 }\end{array}$ & 6MWT & Baseline and yearly thereafter & Retrospective \\
\hline & NCT02663024 & 6MWT & $\begin{array}{l}\text { Baseline and } 25 \text { weeks } \\
\text { posttreatment }\end{array}$ & Prospective \\
\hline \multirow[t]{7}{*}{ Hearing } & $\begin{array}{l}\text { da Silva EMK, et al. } \\
\text { Cochrane Database Syst } \\
\text { Rev. 201I }\end{array}$ & $\begin{array}{l}\text { Audiologic assessment, details not } \\
\text { provided }\end{array}$ & Not reported & Retrospective \\
\hline & $\begin{array}{l}\text { Vellodi A, et al. J. Inher. } \\
\text { Metab. Dis. } \\
\text { 1999;22:638-648 }\end{array}$ & $\begin{array}{l}\text { Griffiths Mental Development Scales } \\
\text { (GMDS) }\end{array}$ & $\begin{array}{l}\text { Pre ( } 2 \text { weeks to several months } \\
\text { prior) and posttransplant (6-12 } \\
\text { months) }\end{array}$ & Prospective \\
\hline & $\begin{array}{l}\text { Keilmann A, et al. J Inherit } \\
\text { Metab Dis. }\end{array}$ & \multirow{2}{*}{$\begin{array}{l}\text { Database review- Hunter Outcome } \\
\text { Survey (HOS): } \\
\text { I. PTA air conduction thresholds } \\
\text { at } 250,500,1000,2000,4000, \\
8000 \mathrm{~Hz}\end{array}$} & $\begin{array}{l}\text { From registration to the last follow- } \\
\text { up }\end{array}$ & Retrospective \\
\hline & $2012 ; 35: 343-353^{11}$ & & & \\
\hline & & $\begin{array}{l}\text { 2. PTAs bone conduction } 250, \\
500,1000,2000,4000 \text { and } 8000 \\
\mathrm{~Hz} \\
\text { 3. Auditory brainstem response } \\
(\mathrm{ABR})^{\mathrm{g}}\end{array}$ & & \\
\hline & $\begin{array}{l}\text { Cho Y, et al. Audiol } \\
\text { Neurotol. 2008;13:206- } \\
212^{23}\end{array}$ & $\begin{array}{l}\text { Click-evoked ABR, Pure tone } \\
\text { audiogram (PTA) }\end{array}$ & I measurement time point ${ }^{c}$ & Prospective \\
\hline & NCT03292887 & $\begin{array}{l}\text { Word recognition test }{ }^{\mathrm{c}} \text {, Bone } \\
\text { conduction }^{\alpha}\end{array}$ & $\begin{array}{l}\text { From registration to the last follow- } \\
\text { up }\end{array}$ & Prospective \\
\hline
\end{tabular}


Table 2. (continued)

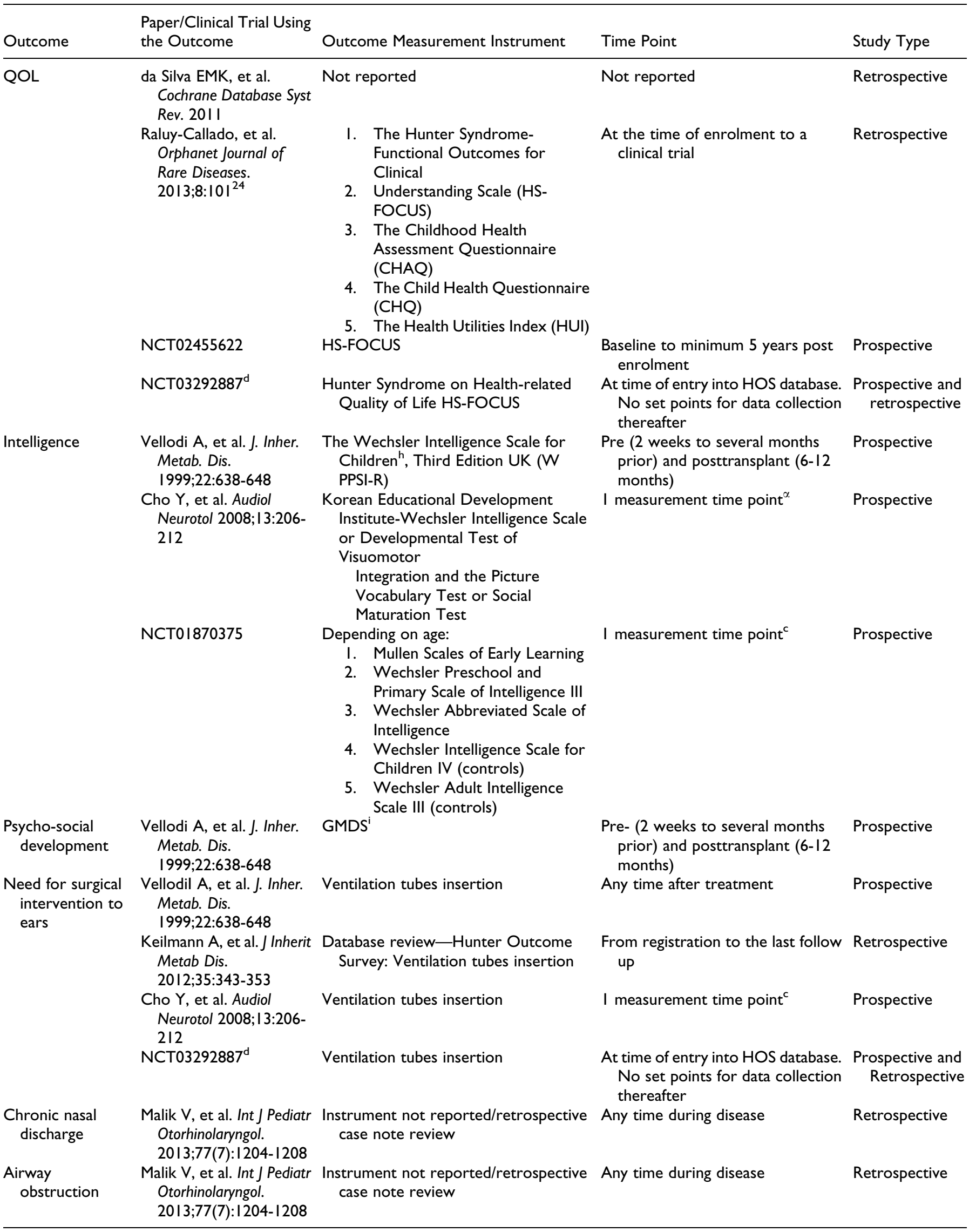


Table 2. (continued)

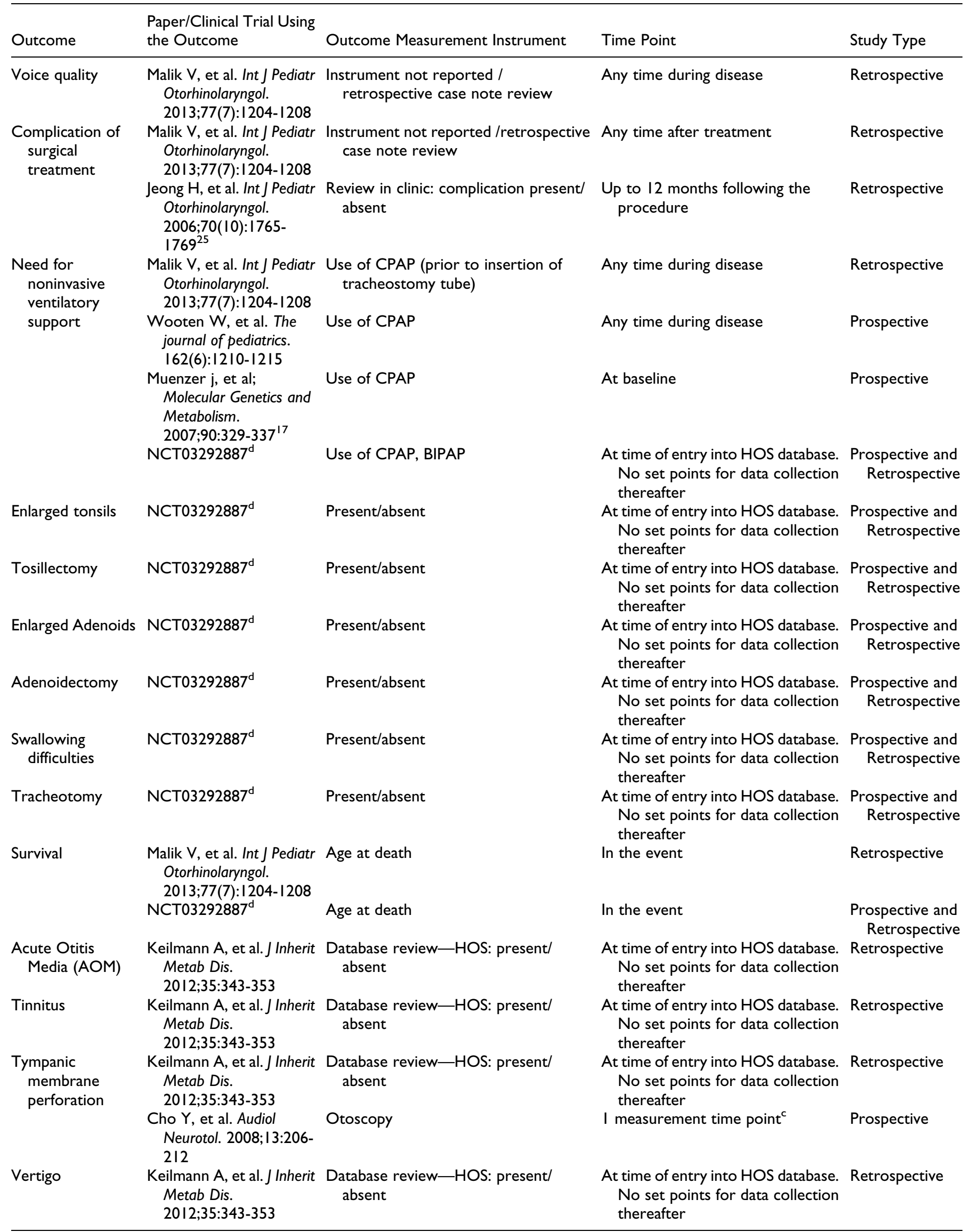


Table 2. (continued)

\begin{tabular}{|c|c|c|c|c|}
\hline Outcome & $\begin{array}{l}\text { Paper/Clinical Trial Using } \\
\text { the Outcome }\end{array}$ & Outcome Measurement Instrument & Time Point & Study Type \\
\hline $\begin{array}{l}\text { Chronic Otitis } \\
\text { Media (COM) }\end{array}$ & $\begin{array}{l}\text { Keilmann A, et al. J Inherit } \\
\text { Metab Dis. } \\
\text { 2012;35:343-353 }\end{array}$ & $\begin{array}{l}\text { Database review-HOS: present/ } \\
\text { absent }\end{array}$ & $\begin{array}{l}\text { At time of entry into HOS database. } \\
\text { No set points for data collection } \\
\text { thereafter }\end{array}$ & Retrospective \\
\hline $\begin{array}{l}\text { Turbulent Ear } \\
\text { Discharge }\end{array}$ & NCT03292887 & Present/absent & $\begin{array}{l}\text { At time of entry into HOS database. } \\
\text { No set points for data collection } \\
\text { thereafter }\end{array}$ & $\begin{array}{l}\text { Prospective and } \\
\text { Retrospective }\end{array}$ \\
\hline \multirow[t]{2}{*}{$\begin{array}{l}\text { Language } \\
\text { development } \\
\text { and } \\
\text { communication } \\
\text { skills }\end{array}$} & $\begin{array}{l}\text { Cho Y, et al. Audiol } \\
\text { Neurotol. 2008;13:206- } \\
212\end{array}$ & $\begin{array}{l}\text { I. Preschool Language Scale, } \\
\text { Picture Vocabulary Test, Test of } \\
\text { Language Development } \\
\text { - Primary } \\
\text { 2. Evaluating Acquired Skills in } \\
\text { Communication } \\
- \text { Revised }\end{array}$ & I measurement time point ${ }^{c}$ & Prospective \\
\hline & NCT03333200 & $\begin{array}{l}\text { No details available on ClinicalTrials. } \\
\text { gov }\end{array}$ & $\begin{array}{l}15 \text { years total: } 3 \text { months the first } \\
\text { year, every } 6 \text { months the second } \\
\text { year and once a year thereafter }\end{array}$ & Prospective \\
\hline \multirow[t]{2}{*}{$\begin{array}{l}\text { Nonsurgical } \\
\text { intervention to } \\
\text { ears }\end{array}$} & $\begin{array}{l}\text { Cho Y, et al. Audiol } \\
\text { Neurotol. 2008;13:206- } \\
212\end{array}$ & Hearing aid: present/absent & I measurement time point ${ }^{\alpha}$ & Prospective \\
\hline & NCT03292887 & Hearing aid: present/absent & $\begin{array}{l}\text { At time of entry into HOS database. } \\
\text { No set points for data collection } \\
\text { thereafter }\end{array}$ & $\begin{array}{l}\text { Prospective and } \\
\text { Retrospective }\end{array}$ \\
\hline $\begin{array}{l}\text { Temporal Bone } \\
\text { status }\end{array}$ & $\begin{array}{l}\text { Cho Y, et al. Audiol } \\
\text { Neurotol. 2008;13:206- } \\
212\end{array}$ & CT & I measurement time point ${ }^{\alpha}$ & Prospective \\
\hline Sinus involvement & NCT03292887 & Present/absent & $\begin{array}{l}\text { At time of entry into HOS database. } \\
\text { No set points for data collection } \\
\text { thereafter }\end{array}$ & $\begin{array}{l}\text { Prospective and } \\
\text { Retrospective }\end{array}$ \\
\hline
\end{tabular}

a Measured by spirometry.

${ }^{b}$ Measured by plethysmography.

'Not standardized for the group.

${ }^{\mathrm{d}}$ Hunter Outcome Survey.

eMeasured by polysomnography.

${ }^{\mathrm{f}} \mathrm{No}$ definition of $\mathrm{AHI}$ in the paper.

${ }^{g}$ No details provided about the test stimulus.

${ }^{\mathrm{h}}$ Verbal IQ, performance IQ and an overall general IQ

'Include the following areas: locomotor, personal-social, hearing and language, eye and hand co-ordination, performance, practical reasoning. 
Table 3. Long-list of outcome measures organised according to COMET COS taxonomy.

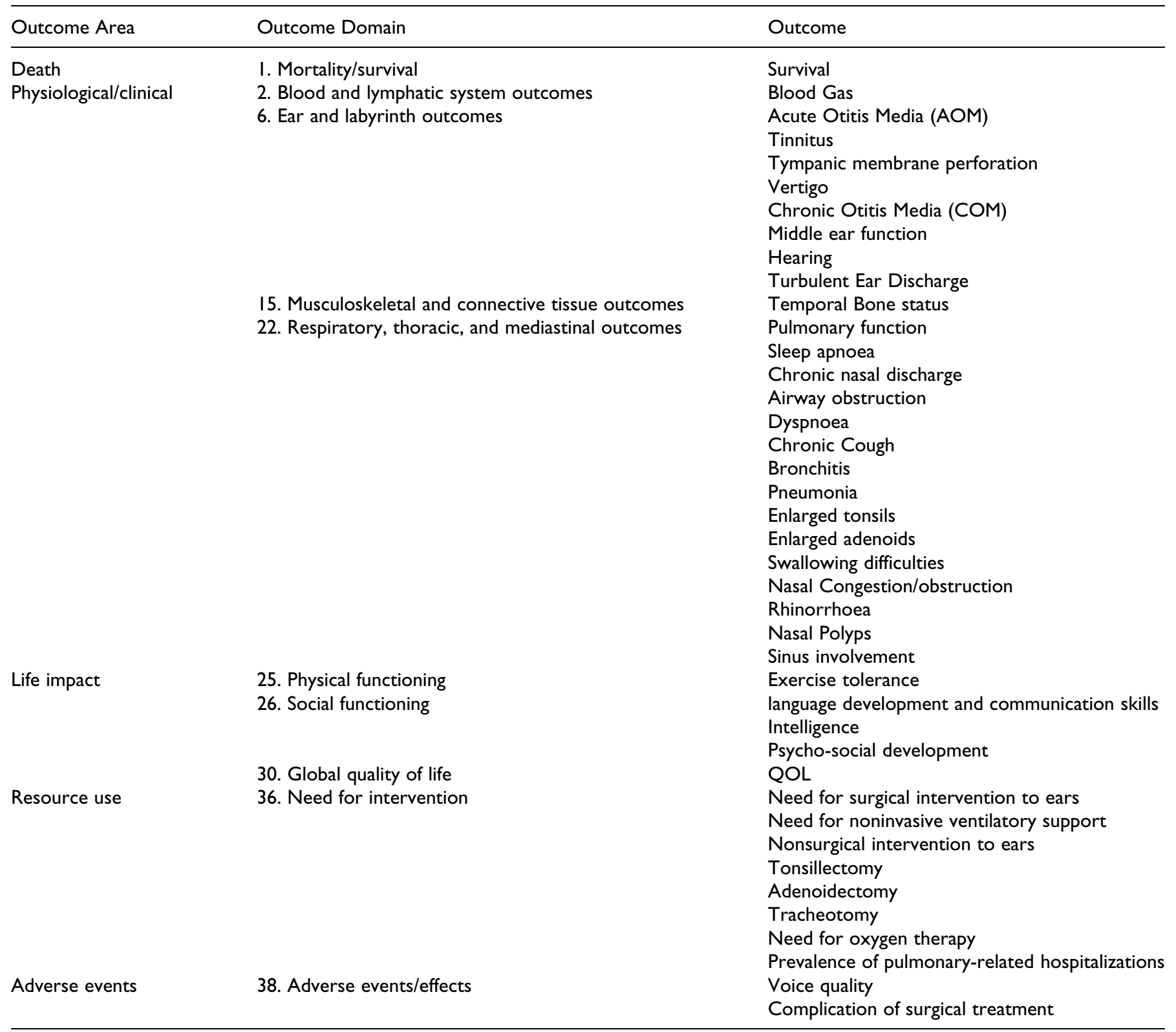

Abbreviation: QoL, quality of life.

secondary outcomes. However, only 1 publication subsequently fulfilled the criteria to be included in the systematic review ${ }^{18}$ and in that study QoL was not measured. The second publication which considered the QoL used 4 different questionnaires of which only 1 was MPS type II specific (HSFOCUS). Mucopolysaccharidosis type II has been shown to be associated with significant impact on the QoL of both patients and their families. ${ }^{24,27}$ Raluy-Callado et al used the Health Utility Index (HUI) which specifically investigated the impact of disease on hearing. They have shown that hearing is the biggest deficiency suffered by patients with MPS type II in agreement with previous publications. ${ }^{5}$ Inclusion of hearing in the HUI makes it particularly relevant for studies involving the head and neck. It is difficult to predict why it was not considered in any of the studies reviewed in this work, although the cost of purchasing a license for use may be a barrier. ${ }^{28}$ Another tool to consider when evaluating head and neck and respiratory-related QoL is HS-FOCUS which measures patient and parental views in 6 areas, including breathing. ${ }^{29}$ The use of QoL scales in complex diseases such as MPS type II presents additional challenges to clinicians and researchers: (1) generic scales may not be sufficiently sensitive or specific to detect meaningful change in the patient cohort, that is, ask the wrong questions and (2) bespoke disease-specific scales may not be validated and we do not understand their utility.

The next step in this project is to use the outcomes "long list" in an eDelphi prioritization and consensus exercise to 


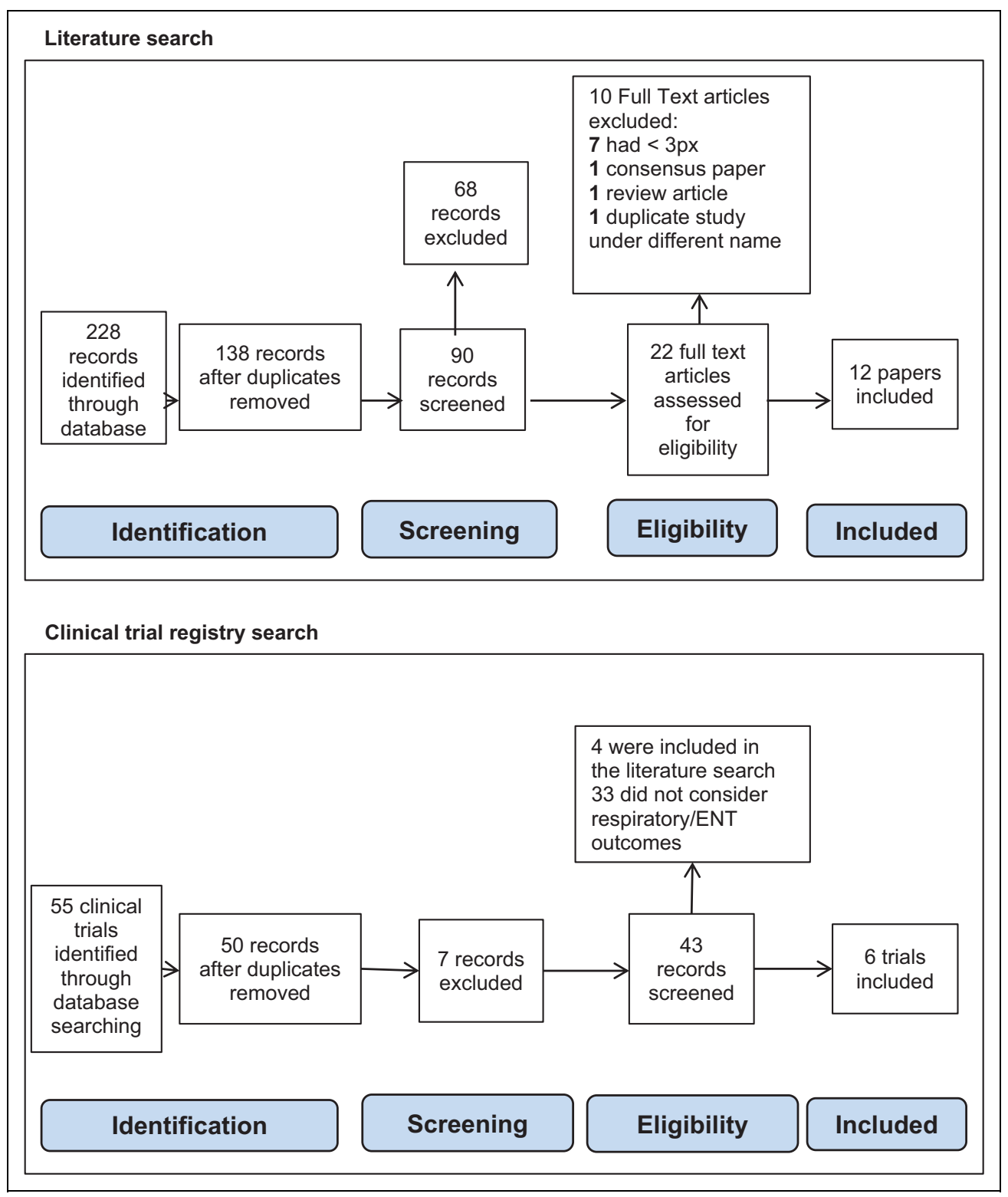

Figure I. Preferred Reporting Items for Systematic Reviews and Meta-analysis (PRISMA) flowchart illustrating the review of methodology.

reach agreement between clinical stakeholder groups (ear, nose, and throat surgeons, metabolic physicians, clinical geneticists, specialist nurses, physiotherapists, and respiratory pediatricians) and patients and parents/carers regarding the most important outcomes to be measured in clinical studies of MPS type II. Involvement of a variety of stakeholders will help ensure that the resultant COS will be inclusive, helpful, and provide a valuable resource for any future clinical studies investigating the head, neck, and respiratory manifestations of MPS type II. Additionally, this study provides a component of the information needed to develop a "general" COS for studies involving patients with MPS type II. Finally, the prioritization and consensus seeking involved in COS development could be used to inform review of the existing HOS database for MPS type II.

\section{Declaration of Conflicting Interests}

The author(s) declared no potential conflicts of interest with respect to the research, authorship, and/or publication of this article.

\section{Funding}

The author(s) disclosed receipt of the following financial support for the research, authorship, and/or publication of this article: This study was supported by an investigator-led research grant from Shire, Zug, Switzerland. IAB and NB are supported by the NIHR Manchester Biomedical Research Centre.

\section{References}

1. Muenzer J. Overview of the mucopolysaccharidoses. Rheumatology (Oxford). 2011;50(suppl 5):v4-v12. 
2. Muenzer EFNJ. 136: the mucopolysaccharidoses. In: Scriver CRBA, Sly WS, et al, eds. The Metabolic and Molecular Bases of Inherited Disease. 8th ed. New York, NY: McGraw-Hill; 2001: 3421-3452.

3. Clark BM, Sprung J, Weingarten TN, Warner ME. Anesthesia for patients with mucopolysaccharidoses: comprehensive review of the literature with emphasis on airway management. Bosn J Basic Med Sci. 2017;18(1):1-7.

4. Jones SA, Almassy Z, Beck M, et al. Mortality and cause of death in mucopolysaccharidosis type II-a historical review based on data from the hunter outcome survey (HOS). J Inherit Metab Dis. 2009;32(4):534-43.

5. Kamin W. Diagnosis and management of respiratory involvement in Hunter syndrome. Acta Paediatr. 2008;97(457):57-60.

6. Rutten M, Ciet P, van den Biggelaar R, et al. Severe tracheal and bronchial collapse in adults with type II mucopolysaccharidosis. Orphanet J Rare Dis. 2016;11:50.

7. Simmons MA, Bruce IA, Penney S, Wraith E, Rothera MP. Otorhinolaryngological manifestations of the mucopolysaccharidoses. Int J Pediatr Otorhinolaryngol. 2005;69(5):589-595.

8. Wooten WI 3 rd, Muenzer J, Vaughn BV, Muhlebach MS. Relationship of sleep to pulmonary function in mucopolysaccharidosis II. J Pediatr. 2013;162(6):1210-1215.

9. Garg RK, Afifi AM, Garland CB, Sanchez R, Mount DL. Pediatric obstructive sleep apnea: consensus, controversy, and craniofacial considerations. Plast Reconstr Surg. 2017;140(5):987-997.

10. Napiontek U, Keilmann A. Hearing impairment in patients with mucopolysaccharidoses. Acta Paediatrica Suppl. 2006;451: 113-117.

11. Keilmann A, Nakarat T, Bruce IA, Molter D, Malm G, Investigators HOS. Hearing loss in patients with mucopolysaccharidosis II: data from HOS - the Hunter Outcome Survey. J Inherit Metab Dis. 2012;35(2):343-353.

12. Peck JE. Hearing loss in Hunter's syndrome-mucopolysaccharidosis II. Ear Hear. 1984;5(4):243-246.

13. Motamed M, Thorne S, Narula A. Treatment of otitis media with effusion in children with mucopolysaccharidoses. Int J Pediatr Otorhinolaryngol. 2000;53(2):121-124.

14. Williamson PR, Altman DG, Blazeby JM, et al. Developing core outcome sets for clinical trials: issues to consider. Trials. 2012;13: 132.

15. Cooney RM, Warren BF, Altman DG, Abreu MT, Travis SP. Outcome measurement in clinical trials for Ulcerative Colitis: towards standardisation. Trials. 2007;8:17.

16. Dodd S, Clarke M, Becker L, et al. A taxonomy has been developed for outcomes in medical research to help improve knowledge discovery. J Clin Epidemiol. 2018;96:84-92.

17. Muenzer J, Gucsavas-Calikoglu M, McCandless SE, Schuetz TJ, Kimura A. A phase I/II clinical trial of enzyme replacement therapy in mucopolysaccharidosis II (Hunter syndrome). Mol Genet Metab. 2007;90(3):329-337.

18. Muenzer J, Wraith JE, Beck M, et al. A phase II/III clinical study of enzyme replacement therapy with idursulfase in mucopolysaccharidosis II (Hunter syndrome). Genet Med. 2006;8(8):465-473.

19. Sohn YB, Cho SY, Park SW, et al. Phase I/II clinical trial of enzyme replacement therapy with idursulfase beta in patients with mucopolysaccharidosis II (Hunter syndrome). Orphanet $J$ Rare Dis. 2013;8:42.

20. da Silva EM, Strufaldi MW, Andriolo RB, Silva LA. Enzyme replacement therapy with idursulfase for mucopolysaccharidosis type II (Hunter syndrome). Cochrane Database Syst Rev. 2011; (11):CD008185.

21. Glamuzina E, Fettes E, Bainbridge K, et al. Treatment of mucopolysaccharidosis type II (Hunter syndrome) with idursulfase: the relevance of clinical trial end points. $J$ Inherit Metab Dis. 2011; 34(3):749-754.

22. Vellodi A, Young E, Cooper A, Lidchi V, Winchester B, Wraith JE. Long-term follow-up following bone marrow transplantation for hunter disease. J Inherit Metab Dis. 1999;22(5):638-648.

23. Cho YS, Kim JH, Kim TW, Chung SC, Chang SA, Jin DK. Otologic manifestations of Hunter syndrome and their relationship with speech development. Audiol Neurootol. 2008;13(3): 206-212.

24. Raluy-Callado M, Chen WH, Whiteman DA, Fang J, Wiklund I. The impact of Hunter syndrome (mucopolysaccharidosis type II) on health-related quality of life. Orphanet J Rare Dis. 2013;8:101.

25. Jeong HS, Cho DY, Ahn KM, Jin DK. Complications of tracheotomy in patients with mucopolysaccharidoses type II (Hunter syndrome). Int J Pediatr Otorhinolaryngol. 2006;70(10):1765-1769.

26. Fernanda HBTAV, Steiner CE, Neto JC, Boy R, Schwartz VD. Medical costs related to enzyme replacement therapy for mucopolysaccharidosis types I, II, and VI in Brazil: a multicenter study. Value in Health Regional Issues. 2015;8(December 2015): 99-106.

27. Guffon N, Heron B, Chabrol B, Feillet F, Montauban V, Valayannopoulos V. Diagnosis, quality of life, and treatment of patients with Hunter syndrome in the French healthcare system: a retrospective observational study. Orphanet $J$ Rare Dis. 2015;10:43.

28. Horsman J, Furlong W, Feeny D, Torrance G. The Health Utilities Index (HUI): concepts, measurement properties and applications. Health Qual Life Outcomes. 2003;1:54.

29. Wiklund I, Raluy-Callado M, Chen WH, Muenzer J, Fang J, Whiteman D. The Hunter Syndrome-Functional Outcomes for Clinical Understanding Scale (HS-FOCUS) Questionnaire: item reduction and further validation. Qual Life Res. 2014;23(9): 2457-2462. 